\title{
Relationship among 5M in the Value Chain of Nanotechnology and Cost Leadership Strategy
}

\author{
Ehsan Abdi ${ }^{1}$ \\ Alireza Rangraz-Jeddi ${ }^{2}$ \\ Nafiseh Ghorbani-Renani² \\ Alireza Azarpajuh ${ }^{3}$ \\ Iman Ghasemi ${ }^{4}$ \\ ${ }^{1}$ Department of Applied Mathematics, School of Mathematics, Iran University of Science and Technology, Tehran, Iran \\ 2 Department of Materials, Manufacturing \& Industrial Engineering, Faculty of Mechanical Engineering, \\ Universiti Teknologi Malaysia (UTM), 81310 Johor Bahru, Malaysia \\ 3 West Virginia University, Morgantown, WV 26506, USA \\ $4^{*}$ Faculty of Management, Universiti Teknologi Malaysia (UTM), International Campus, Kuala Lumpur, Malaysia \\ ${ }^{*}$ Correspondence: Iman Ghasemi (Email: mani_sengani@yahoo.com)
}

\section{Doi:10.5901/mjss.2016.v7n2p343}

\section{Abstract}

In recent decades, nanotechnology is as a main way of in international competitiveness that is due to science and technology. Hence, nanotechnology is known as a new industry or science in the global market competition topics. Most of big companies pursue nanotechnology business in the global market from different products and services through the intensive competitions, especially energy sector in the future. A company can be utilized cost leadership strategy in the value chain of nanotechnology products or services through raw material, machine, manpower, method, and money. Nanotechnology, Nano products and materials can be found as solutions for many existing and latent problems in the future. Consequently, cost leadership and innovation are as strategies for efficiency of services or companies to be frontier in the world. Therefore, this study aims to examine the associations among material, machine, manpower, method, and money in the value chain of nanotechnology and cost leadership. To achieve the aim, seventy questionnaires were distributed among the staffs of two companies of nanotechnology in Iran that are active in production. The sample was selected as Simple Random Sampling (SRS) among their staffs. Quantitative analysis confirmed that there were significant relationships between cost leadership and each independent variable. The minimum correlation was allocated to the relationship between Nano machine and cost leadership ( $r=3.35$, $S D=0.79)$. In addition, maximum correlation was obtained from the relationship between cost leadership and Nano method $(r=3.66, S D=0.64)$.

Keywords: Nanotechnology, Value Chain, Cost Leadership Strategy, Nano Material, Nano Machine, Nano Manpower, Nano Method, Nano Money.

\section{Introduction}

These days, different themes like global warming, scarce of energies and fresh water in the future are very challengeable for the scholars to find remedies for the problems. However, nanotechnology is considered the best choice for coping the problems (Luther, 2008; Kessler \& Charles, 2007). Although the different aspects of utilizing nanotechnology investigated in the academic area, there were weaknesses in cost leadership strategy of the value chain process (Kessler \& Charles, 2007). Besides, the developing and developed countries would trend to gain knowledge and science of nanotechnology for exploiting through economically and environmentally benefits. Further, the researcher believed that providing proper raw material, tools, training forces, approaches and investments is viewed as the high importance from cost leadership strategy in the business of nanotechnology. Consequently, the firms which are in the business of nanotechnology are encountered such problems like commercialization and creating values to be as a competitive company in the global markets (Fiedler \& welpe, 2010; Maine et al., 2012).

Meyyappan (2007) stated that nanotechnology could be employed as Competitive Advantage (CA) strategy to achieve the goals of companies like aerospace industry. For instance, new products of nanotechnology cause to uncover competition as composite materials with a few weights to reach lighter products e.g. missile. In the aim of nanotechnology 
is based on the reducing cost, consistency with environment and getting solution for the problems of human (Lai et al., 2006). So far, nanotechnology products are considered to implement CA strategy in the global markets. While Davies (2010) considered that, they are very useful in the utilizing nanotechnology in food, drug and cosmetic industries with higher quality. For instance, new productions of medicines from nano materials are very intelligent kinds through the technology which are employed to transferring the medicine to human cells. Hence, CA strategies of nanotechnology are more considered in different sectors of the management literature.

By contemplating nanotechnology and management strategies from the academic area, the researcher recognized that the existing associations on the base of the literature among the constructs namely implementing raw material, machine, manpower, method, and money were viewed in cost leadership strategy (Porter, 1985). Hence, the mentioned components of nanotechnology were considered as the antecedent of cost leadership because of employing nanotechnology would be caused saving energies or saving in the cost of producing energies. As well as, it is viewed as the precursor of cost leadership because it causes to discriminate from other competitor companies to get more profits. Hence, the goal of the research is to present the associations between raw material, machine, manpower, method, and money in the value chain of nanotechnology and cost leadership.

\section{Literature Review}

The definition of "Nanotechnology" is due to the compound words of "Nanometer" and Nano equals that means one out of a billion in meters (Kessler \& Charles, 2007). The revolution that is due to nanotechnology can change the old protocols in converting in the impact of new features. The study of Kessler and Charles (2007) proposed that a firm should have good strategies for achieving its goals. If a firm has inflexible without innovation, so it would go in the economically worse. Additionally, formation new features causes to pay attention more because of competitions. According to Luther (2008), improving new technology causes to create new products and services. In addition, the firms will be followed appropriately which employed nanotechnology as using new strategies in the global market. Elcock (2007) believed that it causes to appear new ways for production, distribution and services. The numbers of companies which produce Nanotechnology products as well as their demands are limited. In fact, utilizing of nanotechnology is not clear in business and processing products; it is developed by theories not in actual situations with exception some products. Hence, employing new technology is a necessary point in the business strategy.

According to Sargent (2008), nanotechnology has become as an important topic in the science that can be changed towards the economic, social, even engineering matters. In addition, study of Sargent (2008) has presented that not only the developing of this subject puts in the initial steps but also it is not isolated through the industrial parts. Moreover, Saxton (2007) believed that employing creative techs as nanotechnology can be accounted as new infrastructures in the science for reducing costs especially from environmental aspects. The study of Momaya (2011) has pointed out that developing nanotechnology products or features can be accounted as factors of competition in the different areas of industries because several countries invested in it for the future profits. Sargent (2008) informed that the U.S.A was the first country where producing national technology by investing billions dollars in the early of twenty first century. In addition, Momaya (2011) believed that having nanotechnology knowledge and utilizing it could be considered more from some governments for investing as economical projects in the future strategies.

The application of nanotechnology can be considered in different sectors. So far, different literature presented that nanotechnology can be intervened to find solutions for energy problems. Elcock (2007) believed that different source of energies that are related to nanotechnology are more useful. Although they cannot directly affect, they can contribute to response many demands from different markets. Also, they can influence in consumption pattern. For example, nanotechnology can be divided some areas like Nano crystals, molecular devices, organic transistors and photonic crystals. Moreover, the R\&D of firm can produce new models or products in nanotechnology and would register more than one patent, and then it can take advantage of them in the business (Kessler \& Charles, 2007). Further application of nanotechnology has been stated by Scharff (2012) about the importance of food in the U.S.A from expenditure aspects of people. While the numbers of population are increased in the next few decades, it would cause to raise the demands for food in the world. On the other hand, this would be next challenge to provide food in the future. In addition, the studies like Srinivas et al. (2010) confirmed that the employing nanotechnology in the agriculture for providing food for the population in the world is inevitable. For instance, Scott and Chen (2003) presented that the applications of nanotechnology in the agriculture considered as an agenda for encountering and challenging in relevant food problems. According to Luther (2008), nanotechnology features would be considered for solution of providing potable water and clean water. Additionally, Harper (2007) proposed that using nanotechnology in the energy sector causes to save more from different aspects. 


\subsection{Value Chain Concept}

Generally, value chain is a tool for exploring existing activities in the flow of the business from a firm. May be, the activities are related to different parts of an organization separately from production, delivery to customers, and supportive services. In fact, it can explain different details of business that leads to CA in the markets. According to Porter (1985), the activities are divided into two parts as primary and support activities. Primary activities are directly related to productions and delivering of products (Table 1).

Table 1: Primary Activities

\begin{tabular}{cll}
\hline No. & Primary Activities & Explaining \\
\hline 1 & Inbound logistics & Receiving and storage of external resources \\
2 & Operations & What materials and what products are needed \\
3 & Outbound logistics & Relationships between customers and products \\
4 & Marketing and sales & Attracting customers \\
5 & Services & Giving support service after sale \\
\hline
\end{tabular}

Source: Porter, 1985

In addition, supportive activities are indirectly involved with products or services via effectiveness and efficiency can be led to CA (Table 2).

Table 2: Supportive Activities

\begin{tabular}{lll}
\hline No. & Support Activities & \multicolumn{1}{c}{ Explaining } \\
\hline 1 & Procurement & Necessary resources for business \\
2 & Human Resource Management & Related to forces and organization \\
3 & Technology development & Acquiring and developing information \\
4 & Infrastructure & Finance, planning, quality control, and management \\
\hline
\end{tabular}

Source: Porter, 1985

The process of value chain analysis can be divided in three stages.

1- main activities from leaders of the company

2- assessing company by cost leadership and differentiation strategy

3- determining strategies which can be led to CA

According to Walters (2003), CA cannot be extracted from the traits of company; it should be deduced from different activities that are separately depending on the strategies of the firm. In addition, the strategies can be considered as differentiations through the competitors. In addition, evaluating of activities and interactions of a firm are analyzed by value chain processing to present CA. Consequently, the goals of value chain analysis are mentioned as the following:

1- recognizing activities of a company

2- recognizing relationships and differences in the strategies of a company

3- determining position of company

4- determining alternative value chain in delivery system (Walters, 2003)

\subsection{Nano Value Chain}

In fact, value chain analysis can be considered as a tool which the organization can employ it to achieve CA. It is noticed that by disaggregating an organization into relevant activities for finding out cost behaviors through existing resources and potentials of differentiation (Porter, 1985). In general, a value chain is presented as the processes that are related to technology, material and labor to achieve goals of products or services (Gereffi et al., 2005). In addition, according to Luther (2008), nanotechnology is accounted as a potential in improving efficiency of energy sector and industry. In addition, it can be considered as new technology to achieve economic advantage for companies and enterprises via producing new products that have enhanced properties and innovations in the features. In addition, the different area of 
nanotechnology has involved different stages of value chain. Therefore, according the Porter (1985)'s generic value chain which is mentioned in Fig.1.

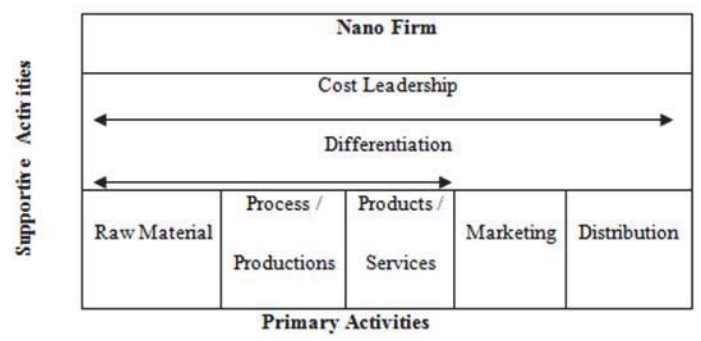

Figure 1: Value Chain of Nanotechnology

Source: Porter, 1985

\section{Research Procedures}

Methodology is a cornerstone of the academic research that can present the route map of a research. It conducts research in the correct way to end up proper results. In addition, it has continuously stages to find appropriate results from the study of the subjects or objects as interesting topics. Since the number of companies which have nanotechnology activities is very limited in Iran. Therefore, the population can be considered not more than 50 companies like SMEs. In addition, the sample of this study was used Simple Random Sampling which was allocated to two companies. As well as, the results can be generalized to whole of the companies in Iran.

\subsection{Data Collection}

The data collection was carried out from two companies of nanotechnology in Iran that are active in the production. In addition, the sample was select as Simple Random Sampling (SRS) among their staffs. In addition, seventy questionnaires distributed, but the returned questionnaires were 66. Further, usable of questionnaires were 63. Therefore, 90 percent of them were employed in data analysis as quantitative research.

\subsection{Data Analysis Method}

In general, the quantitative research can be considered as an important method to find relationships and difference among the major constructs in the study (Hair et al., 2009). Additionally, it needs to provide the conditions for carrying out the research e.g. sampling, SPSS, research model, etc. This study was focused on examining associations among the main variables. Hence, reliability and validity would be important concepts for the data analysis of the research.

\subsubsection{Reliability}

In fact, reliability can be measured by Cronbach's Alpha, it should be more than 0.6 for acceptance. However, Nunnally (1978) believed that the threshold on 0.7 , so higher score can be regarded more reliable questionnaire. On the other hand, the stability of questionnaire can be measured by reliability.

\subsubsection{Validity}

Validity is considered as measuring the instrument in the proper path. It can be presented as content validity and construct validity. Also, content validity can be obtained from the opinion of expertise. In addition, construct validity can account convergent validity and discriminant validity (Hair et al., 2009). 


\subsubsection{Normality}

The normal distribution is the initial step of data analysis in quantitative research (Hair et al., 2009). The bell shape distribution illustrates the symmetric distribution around the mean with the same standard deviation. In this research was considered normality by two tests. First test of normality was considered by Kolmogrov-Smirnov and Shapiro-Wilk tests and also second one would be P-P plot.

\subsubsection{Colinearity}

If the correlations of the manifests are less than 0.9 , so there is no colinearity among the manifests. Hence, it can be considered as discriminant validity (Hair et al., 2009).

\subsubsection{Correlation}

The hypotheses of the current study were focused on the associations between two variables. Additionally, examining association would be carried out by correlation (Hair et al., 2009). If there is a significant correlation, so there is an association between two variables as bivariate correlation.

\section{Results and Discussion}

Table 1 illustrates respondents' rate from distributed questionnaires.

Table 1: Respondents' Rate $(\mathrm{N}=63)$

\begin{tabular}{llcc}
\hline Demographics & Characters & Numbers & Percentages \\
\hline \multirow{2}{*}{ Gender } & Male & 46 & 73 \\
& Female & 17 & 27 \\
\hline \multirow{4}{*}{ Age } & $20-29$ & 18 & 28.6 \\
& $30-39$ & 33 & 52.4 \\
& $40-49$ & 8 & 12.7 \\
\multirow{2}{*}{ Education } & 50 and Higher & 4 & 6.3 \\
\hline \multirow{2}{*}{ Experiences } & Degree & 28 & 44.4 \\
& Master & 28 & 44.4 \\
& PhD & 7 & 11.1 \\
\hline
\end{tabular}

\subsection{Reliability Findings}

The variables i.e. raw material, machine, people, method, money , and cost leadership were examined for reliability by Cronbach's Alpha. Each of them was cut off the acceptance threshold 0.7 (Nuannally, 1978). The reliability whole of questionnaire was 0.87 .

Table 2: Reliabilities

\begin{tabular}{lcc}
\hline Variables & Questions & Cronbach's Alpha \\
\hline Raw Material & $1-3$ & 0.77 \\
Machine & $4-7$ & 0.73 \\
People & $8-12$ & 0.74 \\
Method & $13-16$ & 0.70 \\
Money & $17-21$ & 0.71 \\
Cost Leadership & $22-30$ & 0.73 \\
Questionnaire & $1-30$ & 0.87 \\
\hline
\end{tabular}




\subsection{Validity Findings}

The validity was carried out in two different tests. First was content validity and other one was tested by Principal Component Analysis (PCA) for examining factor loadings, KMO and Bartlett's test.

\subsubsection{Content Validity}

The questionnaire read by professionals and post graduate students for validity. Then the questionnaire was reformed and revised for this research. Also, the questionnaire was read by two bilingual language experts both English and Persian languages to find out better understanding the questions.

\subsubsection{PCA Analysis}

KMO test and Bartlett's test was performed to approving sampling adequacy. Also, KMO test cut off threshold more than 0.5 and Barteltt's test should be significant (Hair et al., 2009).

Table 3: KMO and Bartlett's Test

\begin{tabular}{|l|l|c|}
\hline Kaiser-Meyer-Olkin Measure of Sampling Adequacy. & 0.58 \\
\hline \multirow{3}{*}{ Bartlett's Test of Sphericity } & Approx. Chi-Square & 1134.44 \\
\cline { 2 - 3 } & df & 435.00 \\
\cline { 2 - 3 } & Sig. & 0.00 \\
\hline
\end{tabular}

Moreover, the factor loadings cut off the criterion which should be more than 0.4 from PCA analysis. In addition, the extracted total variance was accounted as 62 percent. All factor loadings were more than 0.4 and validity was established (Hair et al., 2009).

Table 4: Factor Loadings for Validity

\begin{tabular}{ccc|ccc}
\hline Question & Initial & Extraction & Question & Initial & Extraction \\
\hline Q1 & 1.00 & 0.68 & Q16 & 1.00 & 0.74 \\
Q2 & 1.00 & 0.54 & Q17 & 1.00 & 0.65 \\
Q3 & 1.00 & 0.71 & Q18 & 1.00 & 0.68 \\
Q4 & 1.00 & 0.59 & Q19 & 1.00 & 0.42 \\
Q5 & 1.00 & 0.75 & Q20 & 1.00 & 0.51 \\
Q6 & 1.00 & 0.63 & Q21 & 1.00 & 0.52 \\
Q7 & 1.00 & 0.76 & Q22 & 1.00 & 0.50 \\
Q8 & 1.00 & 0.54 & Q23 & 1.00 & 0.73 \\
Q9 & 1.00 & 0.76 & Q24 & 1.00 & 0.63 \\
Q10 & 1.00 & 0.65 & Q25 & 1.00 & 0.72 \\
Q11 & 1.00 & 0.57 & Q26 & 1.00 & 0.66 \\
Q12 & 1.00 & 0.55 & Q27 & 1.00 & 0.52 \\
Q13 & 1.00 & 0.53 & Q28 & 1.00 & 0.41 \\
Q14 & 1.00 & 0.76 & Q29 & 1.00 & 0.54 \\
Q15 & 1.00 & 0.71 & Q30 & 1.00 & 0.64 \\
\hline
\end{tabular}

\subsection{Missing Data and Outliers}

There were just 4 responses as missing data and two outliers. Hence, the outliers deleted and then they were put by the means of each relevant variable.

\subsection{Normality Test}

Normality test of independent variable was carried out by Kolmogorov-Simirnov and Shapiro-Wilk tests. The normality distribution of cost leadership was confirmed, because the tests were insignificant. 
Table 5: Normality Tests

\begin{tabular}{|c|c|c|c|c|c|c|}
\hline & \multicolumn{3}{|c|}{ Kolmogorov-Smirnova } & \multicolumn{3}{c|}{ Shapiro-Wilk } \\
\cline { 2 - 7 } & Statistic & df & Sig. & Statistic & df & Sig. \\
\hline cost Leadership & 0.09 & 63.00 & $0.200^{*}$ & 0.97 & 63.00 & 0.12 \\
\hline
\end{tabular}

Moreover, P-P plot is present normality distribution of each variable. So, all of variables were provided normality distribution by $\mathrm{p}-\mathrm{p}$ plot. In addition the normality of tests for cost leadership was illustrated by P-P plots as the following:

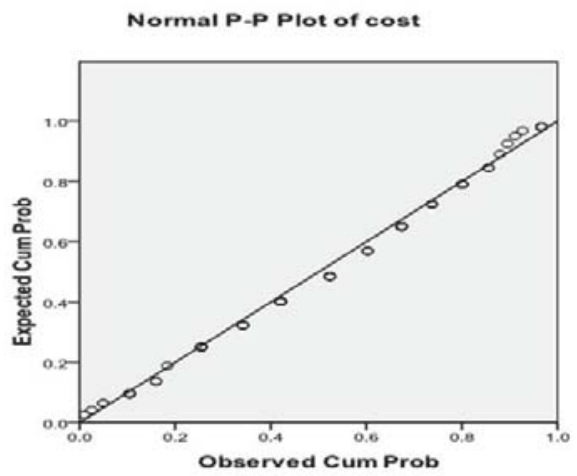

Figure 1: P-P Plot of Cost Leadership

\subsection{Colinearity Findings}

In fact, colinearity test can present each items of the questionnaire not very associated to each other and it can confirm the discriminant validity. Therefore, the following tables presented the all correlations among the variables. the test presented that the main variables were not having high correlation $(>0.9)$, so the discriminant validity was established (Hair et al. , 2009).

Table 6: Colinearity Test

\begin{tabular}{|l|cccccc|}
\cline { 2 - 7 } \multicolumn{1}{c|}{} & Material & Machine & Manpower & Method & Money & Cost \\
\hline Material & 1.00 & & & & & \\
Machine & 0.16 & 1.00 & & & & \\
Manpower & 0.05 & 0.17 & 1.00 & & & \\
\hline Method & 0.24 & $.340^{+*}$ & $.393^{*+}$ & 1.00 & & \\
Money & $.310^{*}$ & 0.16 & $.615^{*+}$ & $.539^{*+}$ & 1.00 & \\
Cost & $.385^{+*}$ & $.306^{*}$ & $.419^{*+}$ & $.366^{*+}$ & $.389^{+*}$ & 1.00 \\
\hline
\end{tabular}

\subsection{Descriptive Statistics}

The main variables were considered as raw material, machine, people, method, and money as independent variables, while cost leadership was regarded as the dependent variable. Also, they would be described by the following:

Table 7: Descriptive Statistics

\begin{tabular}{lccccc}
\hline & $\mathbf{N}$ & Minimum & Maximum & Mean & Std. Deviation \\
\hline Material & 63.00 & 1.00 & 5.00 & 3.40 & 0.90 \\
Machine & 63.00 & 2.00 & 5.00 & 3.33 & 0.79 \\
Manpower & 63.00 & 2.00 & 5.00 & 3.35 & 0.77 \\
Method & 63.00 & 2.00 & 5.00 & 3.66 & 0.64 \\
\hline
\end{tabular}




\begin{tabular}{llllll}
\hline Money & 63.00 & 2.60 & 5.00 & 3.65 & 0.58 \\
Cost & 63.00 & 2.56 & 4.67 & 3.57 & 0.53 \\
Valid N (listwise) & 63.00 & & & & \\
\hline
\end{tabular}

\subsection{Testing Hypotheses}

This research was examined the hypotheses by considering the relationships between cost leadership as the dependent variable and other variables as the independent variables. Hence, each test would be presented separately.

$\mathrm{H} 1$ : There is a significant association between Nano material and cost leadership.

The association between Nano material and cost leadership was examined by the correlation. The relationship was significant between cost leadership and Nano material. Hence, $\mathrm{H} 1$ was supported. Also, the results were presented as the following:

Table 8: Correlation between Cost Leadership and Nano Raw Material

\begin{tabular}{|ll|c|c|}
\hline & & Cost & Material \\
\hline \multirow{3}{*}{ Cost } & Pearson Correlation & 1.00 & $.385^{+*}$ \\
& Sig. (2-tailed) & & 0.00 \\
& $\mathrm{~N}$ & 63.00 & 63.00 \\
\hline \multirow{2}{*}{ Material } & Pearson Correlation & $.385^{+*}$ & 1.00 \\
& Sig. (2-tailed) & 0.00 & \\
& $\mathrm{~N}$ & 63.00 & 63.00 \\
\hline
\end{tabular}

$\mathrm{H} 2$ : There is a significant association between Nano machine and cost leadership.

The association between Nano machine and cost leadership was examined by the correlation. The relationship was significant between cost leadership and Nano machine. Hence, $\mathrm{H} 2$ was supported. Also, the results were presented as the following:

Table 8: Correlation between Cost Leadership and Nano Machine

\begin{tabular}{|ll|c|c|}
\hline & & Cost & Machine \\
\hline \multirow{3}{*}{ Cost } & Pearson Correlation & 1.00 & $.306^{*}$ \\
& Sig. (2-tailed) & & 0.01 \\
& $N$ & 63.00 & 63.00 \\
\hline \multirow{3}{*}{ Machine } & Pearson Correlation & $.306^{*}$ & 1.00 \\
& Sig. (2-tailed) & 0.01 & \\
& $N$ & 63.00 & 63.00 \\
\hline
\end{tabular}

H3: There is a significant association between Nano manpower and cost leadership.

The association between Nano manopower and cost leadership was examined by the correlation. The relationship was significant between cost leadership and Nano manpowere. Hence, $\mathrm{H} 3$ was supported. In addition, the results were presented as the following:

Table 9: Correlation between Cost Leadership and Nano Manpower

\begin{tabular}{|ll|c|c|}
\hline & & Cost & Manpower \\
\hline \multirow{3}{*}{ Cost } & Pearson Correlation & 1.00 & $.419^{*+*}$ \\
& Sig. (2-tailed) & & 0.00 \\
& $\mathrm{~N}$ & 63.00 & 63.00 \\
\hline \multirow{3}{*}{ Manpower } & Pearson Correlation & $.419^{*+*}$ & 1.00 \\
& Sig. (2-tailed) & 0.00 & \\
& $\mathrm{~N}$ & 63.00 & 63.00 \\
\hline
\end{tabular}

$\mathrm{H} 4$ : There is a significant association between Nano method and cost leadership. 
The association between Nano method and cost leadership was examined by the correlation. The relationship was significant between cost leadership and nano method. Hence, H4 was supported. In addition, the results were presented as the following:

Table 10: Correlation between Cost Leadership and Nano Method

\begin{tabular}{|ll|c|c|}
\hline & & Cost & Method \\
\hline \multirow{3}{*}{ Cost } & Pearson Correlation & 1.00 & $.366^{* *}$ \\
& Sig. (2-tailed) & & 0.00 \\
& $N$ & 63.00 & 63.00 \\
\hline \multirow{3}{*}{ Method } & Pearson Correlation & $.366^{* *}$ & 1.00 \\
& Sig. (2-tailed) & 0.00 & \\
& $N$ & 63.00 & 63.00 \\
\hline
\end{tabular}

H5: There is a significant association between Nano money and cost leadership.

The association between Nano money and cost leadership was examined by the correlation. The relationship was significant between cost leadership and Nano money. Hence, H5 was supported. Also, the results were presented as the following:

Table 11: Correlation between Cost Leadership and Nano Money

\begin{tabular}{|cl|c|c|}
\hline & & Cost & Money \\
\hline \multirow{3}{*}{ Cost } & Pearson Correlation & 1.00 & $.389^{*+}$ \\
& Sig. (2-tailed) & & 0.00 \\
& $\mathrm{~N}$ & 63.00 & 63.00 \\
\hline \multirow{3}{*}{ Money } & Pearson Correlation & $.389^{*+}$ & 1.00 \\
& Sig. (2-tailed) & 0.00 & \\
& $\mathrm{~N}$ & 63.00 & 63.00 \\
\hline
\end{tabular}

The quantitative analysis was carried out by the correlations between dependent variables and independent variables. All relationships which were examined confirmed that there was significantly association between cost leadership as the dependent variable and other independent variables.

Table 12: The Results of Hypotheses

\begin{tabular}{lr}
\hline H Hypotheses & Results \\
\hline H1 There is a significant association between nano raw material and cost leadership. Was Supported \\
H2 There is a significant association between nano machine and cost leadership. & Was Supported \\
H3 There is a significant association between nano people and cost leadership. & Was Supported \\
H4 There is a significant association between nano method and cost leadership. & Was Supported \\
H5 There is a significant association between nano money and cost leadership. & Was Supported \\
\hline
\end{tabular}

Quantitative analysis confirmed that there were significant relationships between cost leadership and each independent variable. Hence, the respondents' attitudes were included in the positive relationship between cost leadership and other independent variables namely Nano material, Nano machine, Nano manpower, Nano method, and Nano money. The minimum correlation was allocated to the relationship between Nano machine and cost leadership $(r=3.35, S D=0.79)$. In addition, maximum correlation was obtained from the relationship between cost leadership and Nano method ( $r=3.66$, $\mathrm{SD}=0.64)$.

\section{Conclusion}

The role of nanotechnology, cost leadership and value chain elements of process are uncovered for the investors and marketing professionals. There would be great demands in the future for the Nano products and materials because of the changing technologies and devices. Hence, the functions of firms would be contemplated in nano products in the future. Hence, they should be stayed in CA someday for distinguishing new markets and products. By improving technologies, 
lifestyle and consuming patterns would be changed rapidly at some point. So, saving energies and managing costs would be as the important issues in sustain life as cost leadership strategies

This study shows that each variable in the study i.e. Nano material, Nano machine, Nano manpower, Nano method, and Nano money as 5M of Nano were important components of each Nano companies. In general, they should be considered as the major factors to conduct commercialization of Nano products. Hence, reducing costs during the value chain of Nano production should be controlled in each step for saving time and money. The scientists and professionals forces are very important elements of nanotechnology for innovations and competiveness in the international business new products. Those companies were used the proper strategies in the right time and creating new positions in the global market with high profits. Therefore, the improving nanotechnology business through raw material, manpower, method, money, and machine as constructs affect in the strategy of the firms to achieve more profits.

In sum up, nanotechnology, Nano products and materials can be found as solutions for many existing and latent problems in the future. Investing in the nanotechnology causes to reduce at least greenhouse gases as the global warming challenges. However, sustain life is contemplated as right of next generation, while decreasing the sources of energies in the world. Consequently, cost leadership and innovation are as strategies for efficiency of services or companies to be frontier in the world. Therefore, the firms of nanotechnology perform cost leadership through the innovation in the providing materials, manpower, method, machine, and money. Therefore, Nano businesses have been considered variety of opportunities to select best strategy for cost leadership (Kessler \& Charles, 2007).

\section{References}

Davies, E. (2010). The taste of tiny: Putting nanofoods on the menu. The New Scientist.

Elcock, D. (2007). Potential Impacts of Nanotechnology on Energy Transmission Applications and Needs (p. 36). U.S.

Fiedler, M., \& Welpe, I. M. (2010). Antecedents of cooperative commercialisation strategies of nanotechnology firms. Research Policy, 39(3), 400-410. doi:10.1016/j.respol.2010.01.003

Gereffi, G., Humphrey, J., \& Sturgeon, T. (2005). The governance of global value chains. Review of International Political Economy, 12(1), 78-104. doi:10.1080/09692290500049805

Hair Jr, J. F., Black, W. C., \& Babin, B. J. (2009). Multivariate Data Analysis (7th Editio., p. 816). Prentice Hall.

Harper, T. (2007). Energy And Nanotechnologies: A Rational Market Based Analysis. Nano-Energie Impulsveranstal-Tung, Industrial Park Hanau-Wolf- Gang.

Kessler, E. H., \& Charles, M. (2007). Strategic implications of nanotechnology. Business Strategy Series, 8(6), 401-408. doi:10.1108/ 17515630710684619

Lai, F., Zhao, X., \& Wang, Q. (2006). The impact of information technology on the competitive advantage of logistics firms in China. Industrial Management \& Data Systems, 106(9), 1249-1271. doi:10.1108/02635570610712564

Luther, W. (2008). Application of Nanotechnologies in the Energy Sector (p. 82). HA Hessen Agentur GmbH.

Maine, E., Lubik, S., \& Garnsey, E. (2012). Process-based vs. product-based innovation: Value creation by nanotech ventures. Technovation, 32, 179-192.

Meyyappan, M. (2007). Nanotechnology in Aerospace Applications. Nanotechnology Aerospace Applications.

Momaya, K. (2011). Cooperation for competitiveness of emerging countries: learning from a case of nanotechnology. Competitiveness Review: An International Business Journal Incorporating Journal of Global Competitiveness, 21(2), 152-170. doi:10.1108/1059 5421111117443

Nunnally, J. C. (1978). Psychometric theory (2nd ed., p. 701). McGraw-Hill.

Porter, M. E. (1985). Competitive Advantage: Creating and Sustaining Superior Performance (p. 557). NY: Free Press.

Sargent, J. F. (2008). Nanotechnology and U.S. Competitiveness: Issues and Options (p. 25). United States Congressional Research Service.

Saxton, J. (2007). Nanotechnology: The Future is Coming Sooner Than You Think. Joint Economic Committee, 1-20.

Scharff, R. L. (2012). Economic Burden from Health Losses Due to Foodborne Illness in the United States, 75(1), 123-131. doi:10.4315/0362-028X.JFP-11-058.

Scott, N., \& Chen, H. (2003). Nanoscale science and engineering or agriculture and food systems. U.S.

Srinivas, P. R., Philbert, M., Vu, T. Q., Huang, Q., Kokini, J. L., Saltos, E., ... Ross, S. A. (2010). Nanotechnology research: applications in nutritional sciences. The Journal of Nutrition, 140(1), 119-24. doi:10.3945/jn.109.115048.

Walters, D. (2003). Operations Strategy (p. 270). Palgrave Macmillan. 